\title{
PRIMARY CAVERNOUS HAEMAGIOMA OF THE SKULL: REPORT OF 2 CASES
}

Manglesh Shrivastava ${ }^{1}$, Shilpa U. Vahikar ${ }^{2}$, Kanchan Shrivastava ${ }^{3}$

\section{HOW TO CITE THIS ARTICLE:}

Manglesh Shrivastava, Shilpa U. Vahikar, Kanchan Shrivastava. "Primary Cavernous Haemagioma of the Skull: Report of 2 Cases". Journal of Evolution of Medical and Dental Sciences 2015; Vol. 4, Issue 52, June 29;

Page: 9124-9128, DOI: $10.14260 /$ jemds/2015/1324

ABSTRACT: BACKGROUND: Cavernous haemangiomas are rare benign bone tumours and those at the level of cranial bones are even rarer. The vertebral column is most often affected, followed by the skull. Calvarial cavernous haemangioma is rare, comprising about $0.2 \%$ of all benign neoplasms of the skull. CASE REPORT: We describe here, 2 patients with calvarial cavernous haemangioma that were localized frontally and parietally. The patients were of 45 years and 50 years of age, came with the history of dizziness and headache along with slow growing mass on frontal and parietal region respectively. The mass was soft to firm in consistency with freely mobile skin above the cavernoma sites. A computed tomography scan showed an osteolytic lesion with erosion of tabula externa. Total resection of the lesions and cranioplasty were performed in both the patients.Histopathology of the surgical sample revealed primary osseous cavernous type haemangioma showing large, thin walled, dilated capillary spaces lined by flattened endothelial cells without evidence of malignancy. CONCLUSION: Skull cavernous haemangioma are rare benign tumours. It should always be considered in the differential diagnosis of malignant skull lesions. Histopathological confirmation after surgical resection of tumour is the definitive method of diagnosis.

KEYWORDS: Cavernous haemangioma, Intra-osseous tumour, Skull.

INTRODUCTION: Haemangioma are benign vascular neoplastic disorders. ${ }^{1}$ Toynbee 1845 was the author of the first report in English, a case of haemangioma of the skull bones. ${ }^{2}$

Primary intraosseous cavernous haemangioma (PICH) are benign tumours arising from intrinsic vasculature of bone. ${ }^{3}$

Primary intraosseous cavernous haemangioma are rare, benign skeletal tumours most commonly found in the spinal vertebral column. ${ }^{4}$ Less commonly they can involve the bones of the cranium. ${ }^{4}$ Haemangioma of the skull represent $0.2 \%$ of all osseous tumours and $10 \%$ of all benign tumour of the skull. ${ }^{1}$ Typically cavernous haemangioma grow slowly before they cause symptoms of pain or a visible or palpable skull deformity. ${ }^{5}$

We report two rare cases of skull primary intraosseous cavernous haemangioma presented with slow growing mass on frontal region and parietal region.

Two patients one aged 45 years and other aged 50 years, presented at neurology department with history of dizziness and headache without neurological disturbances.

A 45 years old patient was having a slow growing mass on frontal region while a50 years old man was having mass on parietal region. The masses were soft to firm in consistency with freely mobile skin above the cavernoma sites.

A computed tomography scan was performed in both the cases. It showed an osteolytic lesion with erosion of tabula externa in both the cases. Magnetic resonance imaging performed in one patient showed hypo intense lesion on $\mathrm{T}_{1}$ - weighted images and hyper intense on $\mathrm{T}_{2}$ - weighted image.

Craniotomy and cranioplasty had been performed and tissue sent for histopathological examination in our department. 


\section{CASE REPORT}

Macroscopically both the tissues are bony fragments displayed a purple red discoloration in an area measuring $1.5 \mathrm{cms}$ in diameter on outer surface. The inner table of calvaria was eroded and surrounded by bluish purple tinge.

Microscopy of both the tissues revealed few bony fragments along with large, thin walled dilated, capillary spaces lined by flattened endothelial cells without evidence of malignancy. Dilated capillary spaces are filled with blood.

Immunohistochemical studies showed $\mathrm{CD}_{34}$ positivity in the dilated vascular channels lines by endothelial cells. This finding supported the diagnosis of an intraosseous cavernous haemangioma.

DISCUSSION: Haemangiomas are benign vascular neoplastic disorders that may involve any part of the body. ${ }^{1}$ Histology classifies haemangioma as venous, cavernous and capillary, according to the predominant vascular network. ${ }^{6}$ Although cavernous haemangioma more often involve the brain parenchyma, skull bones may also be affected.

PICHs are rare, benign skeletal tumours, most commonly found in the spinal vertebral column. ${ }^{4}$ Cavernous haemangioma of the skull is a rare pathological diagnosis. ${ }^{7}$ In 1845 , Toynbee first reported a case of cavernous haemangioma of the skull, and this condition was defined by Rowbotham from the histological point of view until $1924 .{ }^{8}$

Within the skull, calvarial haemangiomas are most common than other type of haemangiomas. In a review by Wyke, $70 \%$ of cranial PICHs were localized particularly to the parietal and frontal bones. ${ }^{9}$

Heckle S, Aschoff A \& Kunze S (2002) in their study done on cavernoma of the skull observed that frontal, temporaland parietal bones are the most common sites of cavernous haemangioma of skull in decreasing order. ${ }^{10}$ Intraosseoushaemangioma can also arise from craniomaxillofacial bones. The mandible, zygoma, maxilla \& frontal bones are most commonly involved. ${ }^{4}$ In another review, undertaken by Barnes in 1985, the frontal bone was the most frequently involved site, followed by parietal and zygomatic process. ${ }^{7}$

Our one patient had frontal while other had parietal region involvement.

PICHs commonly occur in middle aged adults in the fourth and fifth decades of life. ${ }^{4}$ Women are two times more commonly affected than men, although paediatric cases are also described. ${ }^{11}$ Our both the patients were males.

Intraosseous cavernous haemangioma is extremely benign, slow growing mostly asymptomatic tumours. As they enlarge, they present as immobile lumps on the head associated with periodic, dull throbbing headaches that occasionally develops into dizziness and severe headaches. ${ }^{4}$ Neurological deficits are unusual because these tumours tend to expand externally but intracranial expansion has been reported.12 Patients may rarely present with an associated epidural haematoma or subarachnoid haemorrhage. ${ }^{6}$

Trauma seems not to be a predisposing factor in the development of these lesions. Haemangioma may be the result of faulty differentiation of primordial vessels, resulting in an abnormal capillary bed.13 There are several known causes for cavernous haemangioma, but some are still unknown. Studies on genes show that specific gene mutations or deletions are causes for the disease. The genes identified are KRIT1, MGC4607 and PDCD10, named CCM1, CCM2 \& CCM3 respectively. The loss of function of these genes is believed to be responsible for cavernous malformations. ${ }^{14}$ 
Grossly, PICHs are soft rubbery, vascular tissue separated by thin bony trabeculae. Cushing described one such lesion as a purplish- black mass and mistakenly suggested as a melanotic sarcoma. ${ }^{15}$

Microscopically, cavernous haemangioma consist of a well-defined non-encapsulated mass, composed of large fully or partially blood filled cavernous vascular spaces, separated by scant connective tissue. ${ }^{1}$ Intravascular thrombosis with associated dystrophic calcification may also be seen. ${ }^{16}$

Capillary haemangiomas are composed of radially directed capillary loops lined by a single layer of cuboidal epithelial cells. Capillary haemangioma may progress to cavernous. ${ }^{17}$

Radiography of the skull is the most useful method to identify PICHs. ${ }^{18}$ In 1930 Bucy and Capp definitely described the radiographic Characteristics as a expansive, well-circumscribed area of rarefaction with a sunburst pattern of trabeculations radiating from a common center. ${ }^{19}$ When viewed enface or on axial views, honeycomb or soap- bubble configuration is characteristic. ${ }^{20}$

CT is an excellent investigation, as it allows detailed characterization of the cortical and trabecular bone to be made. ${ }^{21} \mathrm{MRI}$ investigation is important because of its potential to show soft tissue lesions. ${ }^{22}$ It shows isointense on $\mathrm{T}_{1}$ weighted images and hyperintense on $\mathrm{T}_{2}$ weighted images, consistent with regions of slow flowing blood. ${ }^{13}$ Sometime classic radiographic appearance is not evident. Consequently diagnosis is most often made during surgical resection. These tumours can be misinterpreted as lesions like multiple myeloma or osteosarcoma. ${ }^{23}$

Total surgical resection is the major treatment of skull PICH.18 Because the imaging findings are not specific, pre-operative diagnosis is difficult, histopathology being essential.

CONCLUSION: Skull cavernous haemangioma are rare benign tumours. They do not always have typical radiologic features, so they should always be considered in the differential diagnosis of malignant skull lesions. The preferred treatment is complete tumour removal. Consequently histopathological confirmation after surgical resection is the definitive method of diagnosis.

\section{REFERENCES:}

1. Baltazar Leao Reis, G.T. Cardoso Carvalho, Atos Alves de Sousa, W.B. de Freitas, Rafael Auqusto C. S. Brandao. Primary Haemangioma of the skull. Arg Neuropsiquiatr. 2008; 66 (3-A): 569-571.

2. Toynbee J. An account of two vascular tumours developed in the substance of bone. Lancet. $1845 ; 2: 676$.

3. M. Kilani, M. Darmoul, F. Hammedi, A. Ben Nsir, \& M. N. Hattab. Cavernous Haemangioma of the skull \& Meningioma: Association or Co-incidence \& Case Reports in Neurological Medicine. 2015. Article ID 716837 (http: //dx.doi.org/ 10.1155/2015/716837).

4. James K. Liu, MD, Peter C. Burger, MD, H. RicHarnsberger, MD. Primary intraosseous skull Base cavernous Haemangioma: Case Report. Skull base. 2003 Nov; 13 (4): 219-228.

5. Oren N. Gottfried, MD, Wayne M. Gluf, MD, Meic H. Schmidt, MD. Cavernous haemangioma of the skull presenting with subdural haematoma. Neurosurgery. Focus. 2004; 17 (4).

6. Politi M, Romeike BF, Papanaqiotou P et al. Intraosseous haemangioma of the skull with dural tail sign: Radiologic features with pathologic correlation. AJNR. 2005; 26: 2049-2052.

7. Barnes L. Solitary haemangiomas of bone. In Barnes L (ed): Surgical pathology of the Head and Neck, New York: Dekker. 1985; Vol. 1: pp.932-936. 


\section{CASE REPORT}

8. Madge SN, Simon S, Abidin Z, Ghabrial R, Davis G, McNab A, Selva D. Primary orbital intraosseous haemangioma. OphthalPlastReconstr Surg. 2009; 25 (1): 37-41.

9. Wyke BD. Primary haemangioma of skull. A rare cranial tumour. AJR Am J Roentgenol. 1946; 61: 302-316.

10. Heckl S, Aschoff A, Kunze S. Cavernomas of the skull: review of the literature 1975-200. Neurosurg Rev. 2002; 22: 56-62.

11. Vural M, Acikalin MF, Adapinar B, Atasoy MA. Congenital cavernous haemangioma of the calvaria: Case report. J NeurosurgPediatr. 2009; 3: 41-45.

12. Salba SG, Karam RH, Nehme J1, Nohra GK, Hachem KS, Salloum JW. Intraosseousorbitosphenoidal cavernous angioma. Case Report. J Neurosurg. 1999; 91: 1034-1036.

13. Domenico Murrone, Danilo D Paulis, Daniele F. Millimaggi, Mattia Del Maestro and Renato J Galzia. Cavernous haemangioma of the frontal bone: A case report. Journal of Medical Case Report. 2014; 8: 121.

14. Mouchtouris, Nikolaos, Chalouhi, Nohra, chitale, Ameet, Starke, Robert M. et al. Management of cerebral cavernous malformations: From diagnosis to treatment. The scientific World Journal 2015: 1-8.

15. Cushing H. Surgical end results in general, with a case of cavernous haemangioma of the skull in particular. Surg Gynecol Obstet. 1923; 36: 303-308.

16. Cotran RS, Kumar V, Collins T. Robbins. Pathologic basis of disease. $6^{\text {th }}$ Ed. Philadelphia: W.B. Saunders. 1999.

17. Tsao MN, Schwartz ML, Bernstein M et al. Capillary haemangioma of the cavernous sinus. Report of two cases. J Neurosurg. 2003; 98: 169-174.

18. Peng Xu, Shengyong Lan, Youming Liang, Quan Xiao. Multiple cavernous haemangiomas of the skull with dural tail sign: A case report with literature review. BMC Neurology. 2013; 13: 155.

19. Bucy PC, Capp CS. Primary haemangioma of bone with special reference to roentgenologic diagnosis. AJR Am J Roentgenol. 1930; 23: 1-33.

20. Banerji D, Inao S, Sugita K et al. Primary introsseous orbital haemangioma: A case report and review of literature. Neurosurgery. 1994; 35: 1131-1134.

21. Moore SL, Chun JK, Mitre SA, Som PM. Intraosseous haemangioma of the zigoma: CT \& MR findings. AJNR. 2001; 22: 1383-1385.

22. Amral L, Chiurciu M, Almeida JR, Ferreira NF, Mendonca R, Lima SS, MR imaging for evaluation of lesions of the cranial vault. Arg Neuroposiquiatr. 2003; 61: 521-532.

23. Khanam H, Lipper MH, Wolff CL, Lopes MB. Calvarial haemangiomas: Report of two cases \& review of literature. Surg Neurol. 2001; 55: 63-67. 


\section{CASE REPORT}

Fig. 1: Case 1: Haematoxylin and eosin stained sections showing intra-osseous cavernous haemangioma consisting of thin walled vascular channels lined by flattened epithelium interspersed among bony trabeculae.

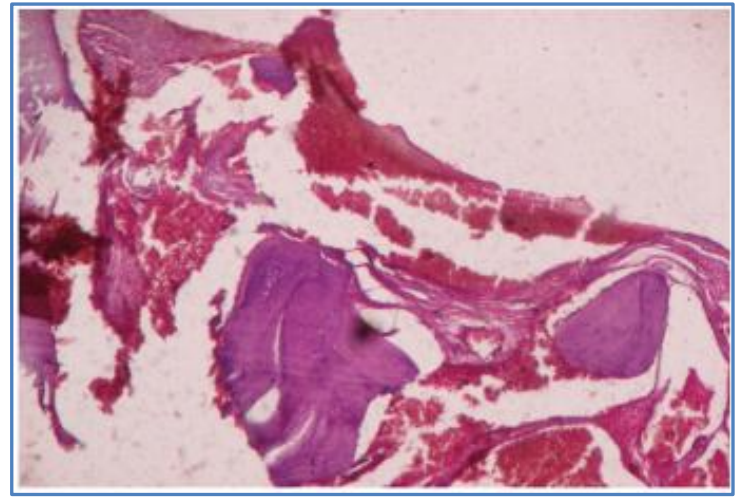

Fig. 1

Fig. 2: Case 2: Haematoxylin and Eosin stained sections showing thin walled dilated blood vascular spaces interspersed amongst bony trabeculae. Dilated capillaries are filled with blood.

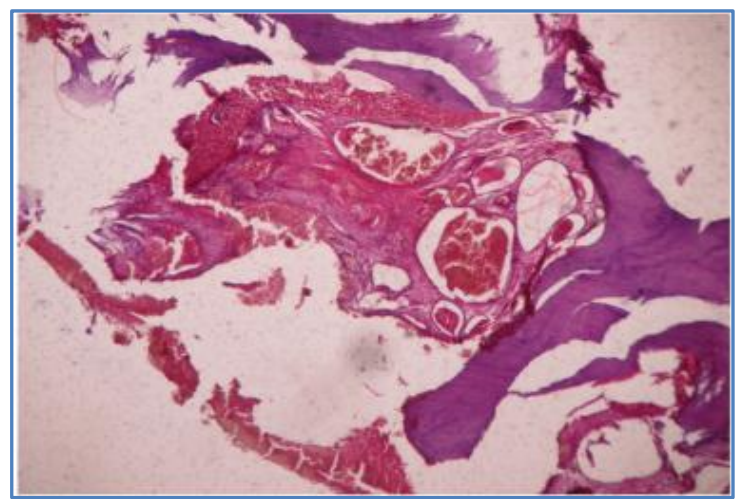

Fig. 2

\section{AUTHORS: \\ 1. Manglesh Shrivastava \\ 2. Shilpa U. Vahikar \\ 3. Kanchan Shrivastava}

\section{PARTICULARS OF CONTRIBUTORS:}

1. Associate Professor, Department of Pathology, Tripura Medical College, Agartala.

2. Assistant Professor, Department of Pathology, BRD Medical College, Gorakhpur.

FINANCIAL OR OTHER COMPETING INTERESTS: None
3. Lecturer, Department of Pathology, BRD Medical College, Gorakhpur.

\section{NAME ADDRESS EMAIL ID OF THE} CORRESPONDING AUTHOR:

Dr. Shilpa U. Vahikar, Department of Pathology, BRD Medical College, Gorakhpur-273013, UP.

E-mail: mall.shilpa@yahoo.co.in

Date of Submission: 05/06/2015. Date of Peer Review: 08/06/2015. Date of Acceptance: 20/06/2015. Date of Publishing: 29/06/2015. 